Forthcoming in: Opris, Ioan and Casanova, Manuel, F. (2017). The Physics of the Mind and Brain Disorders: Integrated Neural Circuits Supporting the Emergence of Mind (Springer Series in Cognitive and Neural Systems). Cham: Springer.

\title{
Pharmacological Interventions and the Neurobiological Basis of Mental Disorders
}

\author{
Jonathan Y. Tsou \\ Department of Philosophy and Religious Studies, Iowa State University
}

Mailing address: Jonathan Y. Tsou, Department of Philosophy and Religious Studies, Iowa State University, 402 Catt Hall, Ames, IA, USA, 50011.

Email: jtsou@iastate.edu

Keywords: psychiatry, pharmacology, neurobiology, neuroscience, biological basis of mental disorders, dopamine hypothesis of schizophrenia, serotonin hypothesis of depression, interventionist accounts of causation 


\section{Introduction}

In psychiatry, pharmacological research has played a crucial role in the formulation, revision, and refinement of neurobiological theories of psychopathology. Besides being utilized as potential treatments for various mental disorders, pharmacological drugs play an important epistemic role as experimental instruments that help scientists uncover the neurobiological underpinnings of mental disorders (Tsou, 2012). Interventions with psychiatric patients using pharmacological drugs provide researchers with information about the neurobiological causes of mental disorders that cannot be obtained in other ways. This important source of evidence for the biological causes of mental disorder is often overlooked in philosophical analyses of psychiatry, especially in skeptical analyses that debase the biological aspects of psychopathology (e.g., Szasz, 1960; Scheff, 1963; Laing, 1967). In discussing pharmacological interventions as a form of evidence for the physical basis of mental disorders, this paper aims to clarify the nature, reliability, and limitations of this evidence. In addition, it illustrates the central role that pharmacological findings in applied clinical contexts play in the acquisition of neurobiological knowledge in research contexts.

The main argument advanced in this paper is that pharmacological interventions with clinical populations of psychiatric patients allow scientists to draw causal inferences about the neurobiological basis of mental disorders. While the knowledge acquired in this process is not infallible or immune to revision, pharmacological interventions are indispensable in the articulation of scientific knowledge about the neurobiological causes of mental disorders. I advance this argument with reference to the development of neurobiological theories of schizophrenia and depression in the second half of the twentieth century. My analysis of these historical cases emphasizes the indispensable role that pharmacological interventions played in 
the articulation of the dopamine hypothesis of schizophrenia and the serotonin hypothesis of depression. I subsequently discuss three specific epistemic functions that pharmacological drugs serve in contributing to knowledge about the neurobiological basis of mental disorders: (1) facilitating the generation and formulation of etiological neurobiological hypotheses, (2) aiding in the testing and confirmation of neurobiological theories, and (3) permitting the refinement, elaboration, and revision of existing neurobiological theories. In the history of neurobiological theories of schizophrenia and depression, pharmacological drugs functioned as experimental instruments that realized each of these functions.

My analysis of pharmacological interventions in psychopathology research draws on philosophical accounts of science that emphasize the importance of manipulability and intervention in experimental contexts (Cartwright, 1983, ch. 5; Hacking, 1983; Ackermann, 1985; Franklin, 1986, 1996, 2010; Giere, 1988, ch. 5; Woodward, 2003, 2008). These philosophical analyses suggest that intervening with and manipulating theoretical (i.e., unobservable) entities in systematic ways provides philosophical reasons for believing in their existence (cf. Morrison, 1990). While philosophers such as Ian Hacking (1983) maintain that experimentation with theoretical entities (e.g., manipulating electrons in electron guns) provides evidence for their real existence, my analysis takes the more liberal stance that experimentation on entities and measuring their properties can sometimes provide reasons for believing in their existence (Franklin, 1996, 2010). In the case of mental disorders, my analysis suggests that there is defeasible evidence for believing that a mental disorder is a real theoretical entity (as opposed to a social construction) when it can be manipulated in systematic and predictable ways by pharmacological drugs. What pharmacological interventions ultimately reveal is the stable biological causal structure of these disorders and the specific neurobiological mechanisms that 
underwrite them.

\section{Antipsychotic Drugs and Schizophrenia}

Knowledge about the neurobiological causes of schizophrenia is known largely through various pharmacological interventions with antipsychotic drugs. The first antipsychotic drug (chlorpromazine) was discovered by accident in the early 1950s, which was followed by the development of other antipsychotic drugs in the 1960s and 1970s. Pharmacologists' attempt to remove the unwanted extrapyramidal side-effects associated with these first generation antipsychotic drugs led to the creation of second-generation, atypical antipsychotic drugs in the 1990s. All of these developments in pharmacology were important steps in the formulation of the dopamine theory of schizophrenia and led to a greater understanding of the neurobiological basis of schizophrenia.

In the early 1950s, a French military surgeon, Henri Laborit, was experimenting with various drugs that could potentially treat surgical shock, which is an acute and sometimes fatal state that occurred during surgery (McKim, 2007, pp. 287-288). Laborit hypothesized that surgical shock is caused by the excessive release of neurotransmitters, such as epinephrine, acetylcholine, and histamine; and he experimented with drugs that were known to block the release of these substances, including various antihistamines. In 1951, Laborit was able to successfully treat surgical shock with an antihistamine called RP-4560 (chlorpromazine), and he reported that he was able to put surgical patients into an 'artificial hibernation,' wherein patients would not lose consciousness, but become sleepy and disinterested with their surroundings (Laborit \& Huguenard, 1951). Laborit speculated about potential therapeutic applications of 
chlorpromazine in psychiatry and suggested to some psychiatric colleagues that the drug might be useful for treating agitated mental patients (Ban, 2007, p. 496; Healy, 2002, pp. 81-82).

The most important clinical trials with chlorpromazine were conducted by two Parisan psychiatrists, Jean Delay and Pierre Deniker, who learned of Laborit's trials and began using chlorpromazine to treat psychiatric patients (López-Muñoz et al., 2005, p. 118). In 1952, Delay and Deniker reported that while chlorpromazine was not successful in treating depression, it had dramatic therapeutic effects on patients in states of agitation, mania, mental confusion, and acute psychosis (López-Muñoz et al., 2005, p. 120). The researchers also reported the drug’s capacity to slow motor activity, cause affective indifference, and neutralize emotions as a 'neuroleptic syndrome’ (Delay \& Deniker, 1952).

In November 1952, chlorpromazine was made available for prescription in France under the tradename Largactil, which made the drug widely available to clinicians and psychiatrists around the world (Shen, 1999, pp. 408-409). In 1954, Heinz Lehmann, a German born Canadian psychiatrist, suggested that chlorpromazine worked by selectively inhibiting 'affective drive' (Lehmann, 1954; Lehmann \& Hanrahan, 1954), and his research was highly influential in promoting the use of chlorpromazine in North American psychiatry. By the end of 1955, successful treatment of schizophrenic patients with chlorpromazine were reported in numerous countries in the world, including Switzerland, the United Kingdom, Germany, Hungary, Canada, Peru, the United States, Australia, and the Soviet Union (Ban, 2007, p. 296). In 1957, the American Public Health Association jointly awarded the prestigious Lasker Prize for Medicine to Laborit, Deniker, and Lehmann for discovering the antipsychotic properties of chlorpromazine (Ban, 1994; Healy, 2002, pp. 125-128). 
The success in treating schizophrenic patients with chlorpromazine in the 1950s stimulated the search for other antipsychotic drugs, and a number of other drugs with similar antipsychotic effects (e.g., thioridazine, fluphenazine, haloperidol) were developed in the 1960s and 1970s (Healy, 2004, pp. 96-7). A common problem with these first-generation (“typical”) antipsychotic drugs was the presence of unwanted motor side-effects or extrapyramidal symptoms (EPS) that resemble the symptoms of Parkinson's disease; EPS include symptoms such as muscular rigidity (dystonia), abnormal motion of voluntary and involuntary muscles (dyskinesia), inability to initiate movement (akinesia), inability to remain still (akasthesia), and tremors (Kring et al., 2007, p. 375). In a 1961 report, the prevalence of EPS among patients treated with antipsychotic drugs was estimated to be 38.9\% (Ayd, 1961), and many pharmacologists at the time believed that there was an absolute inverse relationship between the clinical efficacy of an antipsychotic drug and EPS, with stronger antipsychotic effect being associated with more EPS (Shen, 1999, p. 409). This belief was refuted with the development of second-generation (“atypical”) antipsychotic drugs.

While the first atypical antipsychotic drug was first synthesized in 1958, these drugs were not significantly utilized in clinical settings until the 1990s because of concerns regarding their safety. The first atypical antipsychotic drug that was developed was clozapine. This drug was developed by a research team directed by Hanns Hippius in Switzerland, who-in the early 1960s - were attempting to refute the common pharmacological belief that EPS and strength of antipsychotic effect were causally linked (Hippius, 1996). Several clinical trials indicated that clozapine had a strong antipsychotic effect with minimal EPS (Bente et al., 1966; Gross and Langer, 1966; Angst et al., 1971), which demonstrated that the clinical efficacy of antipsychotic drugs could be decoupled from their unwanted side-effects. Clozapine was introduced in clinical 
settings in a number of European countries in the late-1960s; however, it was withdrawn from the market in many countries by the mid-1970s due to concerns that agranulocytosis (i.e., a lifethreatening lowering of white blood cells) was caused by clozapine treatment (Healy, 2002, pp. 238-244). In the following decade, fears about the safety of clozapine allayed, and it became understood that agranulocytosis would appear for a small percentage of patients, but fatalities could be avoided through close blood monitoring (Hippius, 1989, p. S4). In the United States, the introduction of clozapine was facilitated by a landmark study that demonstrated the effectiveness of clozapine (compared to chlorpromazine) on treatment-resistant schizophrenic patients (Kane et al., 1988). After clozapine was introduced in the US, a number of other atypical antipsychotic drugs (e.g., risperidone, olanzapine, aripiprazole) were quickly developed in the 1990s and 2000s (Janowsky, 2004, pp. 80-81); all antipsychotic drugs currently under development are of the atypical type.

In addition to being employed as tools for treating schizophrenic patients, antipsychotic drugs — and pharmacological drugs more generally_function as experimental instruments for identifying the neurobiological causes of schizophrenia. In particular, pharmacological interventions with schizophrenic patients have played a central epistemic role in the formulation, revision, and refinement of the dopamine hypothesis of schizophrenia, which has been the dominant neurobiological theory of schizophrenia since the 1970s (Kring et al., 2007, pp. 363365; Carlson, 2008, pp. 460-466). In its original formulation, the dopamine hypothesis suggested that the symptoms of schizophrenia are caused by excessive activity of the neurotransmitter dopamine. Since the early 1980s, the symptoms of schizophrenia have been distinguished into ‘positive symptoms’ and ‘negative symptoms’ (Strauss, Carpenter, and Bartko, 1974; Wing, 1978; Crow, 1980a, 1980b; Andreason and Olsen, 1982): 
(1) Positive symptoms (psychological excesses): delusions, hallucinations, and disordered thought.

(2) Negative symptoms (psychological deficits): flattened emotions, poverty of speech, lack of motivation, and social withdrawal.

As discussed below, a more refined formulation of the dopamine hypothesis maintains that the positive (psychotic) symptoms of schizophrenia are caused by excessive dopamine activity. Evidence for this qualified dopamine hypothesis is supported by various pharmacological interventions. All antipsychotic drugs—-typical and atypical—that can successfully treat the positive symptoms of schizophrenia are dopamine antagonists that decrease the activity of dopamine. A key discovery in the 1970s that further implicated the role of dopamine was the finding that the clinical efficacy of typical antipsychotics (e.g., chlorpromazine, haloperidol) is directly related to their affinity for dopamine receptors (Seeman et al., 1975). Indirect evidence for the dopamine hypothesis was provided by the fact that typical antipsychotic drugs cause EPS similar to the symptoms of Parkinson's disease, and Parkinson's is known to be cause, in part, by low levels of dopamine (Kring et al., 2007, p. 363). Another important piece of evidence was the finding in the early 1970s that stimulant drugs (e.g., amphetamine, cocaine) with opposite pharmacological effects as antipsychotics (i.e., dopamine agonists), when taken in sufficiently large doses, induce an 'amphetamine psychosis' that is indistinguishable from the positive symptoms of schizophrenia; and this state can be treated with antipsychotic drugs (Ellinwood, 1967; Ellinwood, Sudilovsky, and Nelson, 1973).

In the early 1990s, a further elaboration of the dopamine hypothesis was articulated in a landmark paper (Davis et al, 1991), which expanded the scope of the original dopamine hypothesis by theorizing about different dopamine systems and receptors (Healy, 2002, chs. 5- 
6). This revised dopamine hypothesis suggests that excessive dopamine activity in the mesolimbic pathway is responsible for the positive symptoms of schizophrenia, while deficient dopamine activity in the mesocortical pathway is responsible for the negative symptoms. The mesolimbic dopamine pathway (which is involved in motivation and reinforcement) is a neural pathway that originates in the ventral tegmental area and projects to the hypothalamus, amygdala, hippocampus, and nucleus accumbens (Kring et al., 2007, p. 364; McKim, 2007, pp. 289-290). The original hypothesis that schizophrenia is caused by excessive dopamine activity was refined to the narrower hypothesis that the positive symptoms are caused by excessive dopamine activity in the mesolimbic pathway. This excessive activity is theorized to be caused by hyperstimulation of $\mathrm{D}_{2}$ dopamine receptors (the main dopamine receptor in this pathway) given that antipsychotic drugs exert their therapeutic effect by blocking $\mathrm{D}_{2}$ receptors (AbiDargham, 2004). The revised dopamine hypothesis also suggests that deficient dopamine activity in the mesocortical pathway—and in particular, the prefrontal cortex—results in the hypostimulation of $\mathrm{D}_{1}$ receptors (the main dopamine receptor subtype in this area), which is responsible for the negative symptoms and cognitive impairments associated with schizophrenia (Abi-Dargham, 2004). The mesocortical dopamine pathway originates in the ventral tegmental area and projects to the prefrontal cortex (Kring et al., 2007, p. 364). The hypothesis that negative symptoms are caused by deficient dopamine activity in the mesocortical pathway is supported by the facts that cognitive impairment is associated with dysfunction in the prefrontal cortex (the terminal region of the mesocortical pathway) and dopamine depletion in the prefrontal cortext (using dopamine antagonists) in animals induces cognitive impairment (Sawaguichi and Goldman-Rakic, 1994). Moreover, deficits in dopamine activity in the mesocortical pathway are causally related to excessive dopamine activity in the mesolimbic 
pathway. The prefrontal cortex projects to limbic areas innervated by dopamine such that deficient dopamine activity in the prefrontal cortex fails to exert inhibitory control over dopamine neurons in the limbic area, resulting in excessive dopamine activity in the mesolimbic system (Kring et al., 2007, pp. 364-365; Carlson, 2008, pp. 468-469). Hence, the original dopamine hypothesis posited in the 1970s was expanded from the hypothesis that schizophrenia is caused by excessive dopamine activity to the theory that schizophrenia is caused by a dysregulation of dopamine, with deficiency of dopamine activity in the prefrontal cortex resulting in an excess of dopamine activity in the mesolimbic pathway. While dysregulation of dopamine cannot tell the complete story about schizophrenia (Kendler and Schaffner, 2011), abnormalities in the dopamine system are undoubtedly an important causal factor in schizophrenia.

\section{Antidepressant Drugs and Depression}

Like schizophrenia, knowledge about the neurobiological basis of depression is largely known through various pharmacological interventions with antidepressant drugs. The antidepressant properties of the first two classes of antidepressant drugs (i.e., monoamine oxidase inhibitors and tricyclic antidepressants) were discovered by accident in the 1950s. The attempt to develop safer antidepressants with fewer side-effects led to the self-conscious design of second-generation antidepressants (i.e., selective serotonin reuptake inhibitors), which were introduced to the market in the 1980s. All of these pharmacological developments in antidepressant drugs contributed to the formulation of the serotonin theory of depression and our current understanding of the neurobiological basis of depression. 
The first successful antidepressant drug was iproniazid, and its antidepressant properties were discovered by accident while it was being experimented on as a potential treatment for tuberculosis (Hirschfeld, 2000). In 1952, during clinical trials of iproniazid for tuberculosis patients in the United States, it was discovered that this drug significantly elevated the mood of patients; subsequent trials established that this antidepressant effect was independent of its ability to treat tuberculosis (McKim, 2007, pp. 301-302). In 1957, at a meeting of the American Psychiatric Association in Syracuse, New York, data on the effectiveness of iproniazid to treat depression was presented. A year after this meeting, over 400,000 patients affected by depression had been treated with the drug, despite the fact that iproniazid was being marketed as an antitubercular agent (López-Muñoz and Alamo, 2009, p. 1566-1567). Iproniazid turned out to be the first of the monoamine oxidase inhibitor (MAOI) antidepressants, and research into other MAOIs (e.g., isocarboxazid, phenelzine, tranylcypromine) to treat depression soon followed (López-Muñoz et al., 2007, p. 557). While MAOIs were widely used in the 1960s, enthusiasm for them waned by the 1970s because of concerns about MAOIs causing liver damage and potentially dangerous interactions with other drugs and foods. Newer MAOIs have been developed that are more specific in their actions, reversible, and less likely to interact with foods (McKim, 2007, p. 301).

Another class of antidepressant drugs that were developed in the 1950s were tricyclic antidepressant (TCA) drugs, which were discovered by accident during trials to test antipsychotic drugs (Healy, 1997, ch. 2). In the mid-1950s, the (typical) antipsychotic drug impramine was being tested on schizophrenic patients in Switzerland; while this drug was not effective at treating psychosis, it was found to elevate the mood of depressed patients (McKim, 2007, p. 301). Subsequent trials by Roland Kuhn, who was Medical Director at the Psychiatric 
Clinic of Thurgau Canton, indicated that imipramine could improve the mood of depressed patients (López-Muñoz and Alamo, 2009, pp. 1569-1571). By 1958, the antidepressant effects of imipramine were confirmed and it was placed on the market in Europe. In North America, the use of imipramine to treat depression was initiated by Heinz Lehmann, who conducted a study on impipramine on depressed patients that allowed the drug to be marketed in the United States (Lehmann, Cahn, and De Verteuil, 1958). A landmark study published in 1965 (Klerman and Cole, 1965) demonstrated that imipramine was superior to placebo in the treatment of depression. Following the clinical success of imipramine, a number of other TCAs (e.g., desipramine, protryptyline, clomipramine) were developed in the 1960s (Fangmann et al., 2008). The unwanted side-effects of TCAs, due to their cardiotoxicity and anticholinergic properties, spurned the search for other antidepressants.

Unlike the fortuitous discovery of the antidepressant properties of MAOIs and TCAs, selective serotonin reuptake inhibitor (SSRI) antidepressants were developed following a procedure of directed design (Wong, Perry, and Bymaster, 2005). MAOIs and TCAs provided crucial information regarding what kinds of pharmacological actions were causing antidepressant effects, which allowed pharmacologists to design drugs that would have effects at a specific locus of action (López-Muñoz and Alamo, 2009, pp. 1576-1578). In the 1970s, the American pharmaceutical company Eli Lilly synthesized the SSRI, fluoxetine. A pioneering paper by David Wong's research group at Lilly described the actions of fluoexetine on reuptake systems and discussed the potential of this drug for understanding serotonin function and for treating depression (Wong et al., 1974). In 1980, Lilly committed to studying fluoexetine and enlisted the psychiatrist John Feighner to conduct clinical trials on the drug. These studies suggested that fluoexetine was as effective as TCAs, but with far fewer adverse side-effects, which led Feighner 
to write of the “new generation of antidepressants” (Feighner, 1983). In 1987, the FDA approved of the clinical use of fluoexetine, which was marketed under the tradename Prozac; by 1990, fluoexetine was the most widely prescribed drug by North American psychiatrists (López-Muñoz and Alamo, 2009, p. 1578). Following the clinical success of fluoexetine, other SSRIs (e.g., citalopram, sertraline, paroxetine) were quickly placed on the market (López-Muñoz and Alamo, 2009, p. 1578).

As in the case of antipsychotic drugs and schizophrenia, pharmacological interventions with antidepressant drugs have been crucial experimental tools in uncovering the neurobiological basis of depression (Tsou, 2013). In particular, pharmacological research played a central role in the discovery, articulation, and revision of the monoamine hypothesis of depression. The first articulation of the monoamine hypothesis in the 1960s suggested that depression is caused by deficient activity of monoamine neurotransmitters: norepinephrine (NE), serotonin (5-HT), and dopamine (DA). The monoamine hypothesis was formulated largely based on the fact that MAOIs and TCAs that can relieve the signs of depression are monoamine agonists that increase the activity of monoamine neurotransmitters. Furthermore, monoamine antagonist drugs with opposite pharmacological effects of the first-generation antidepressants (e.g., reserpine) can induce depressive symptoms in non-depressed individuals (Sachar and Baron, 1979).

By the end of the 1960s, the monoamine hypothesis became revised to the serotonin hypothesis of depression. The serotonin hypothesis suggests that depression is caused by deficient activity of serotonin in the serotonin pathway that begins in the Raphé nuclei and projects through the medial forebrain bundle to the forebrain (McKim, 2007, p. 304). This hypothesis gained support among researchers after studies demonstrated the powerful inhibition of serotonin reuptake in imipramine and other TCAs, which function to increase serotonin 
activity (López-Muñoz and Alamo, 2009, p. 1577). The serotonin hypothesis was also supported by the fact that SSRIs, which also function to increase the activity of serotonin, are effective at alleviating depression among a broad range of patients, although their relative efficacy among patients with severe depression is controversial (Hirschfeld, 2000).

Besides pharmacological research, the serotonin hypothesis of depression is also supported a number of other independent findings. Lower production of and release of serotonin in the brain is correlated with decreased Cerebrospinal Fluid (CSF) levels of 5hydroxindoleacectic acid (5-HIAA), which is the main metabolite of serotonin; studies have shown significantly lower CSF levels of 5-IAA among individuals who have attempted suicide, and lower levels of 5-HIAA are correlated with a higher number of suicide attempts ( $\AA$ sberg, Träskmann, \& Thorén, 1976; Roy, De Jong, \& Linnoila, 1989; Träskmann et al., 1981). Postmortem studies have identified increased numbers of postsynaptic serotonin receptors (e.g., 5$\mathrm{HT}_{1 \mathrm{~A}}$ and 5- $\mathrm{HT}_{2 \mathrm{~A}}$ receptors), in the prefrontal cortex of suicide victims, possibly due to a compensatory response to reduced serotonin activity (Mann, 1998, p. 26). Moreover, tryptophan depletion studies have demonstrated that lowering levels of tryptophan (the main precursor to serotonin), which lowers serotonin levels in individuals, causes temporary depressive symptoms among individuals with a history of depression, but not for individuals without a history of depression (Benkelfat et al., 1994; Johnson et al., 2009, pp. 203-204; Moore at al., 2000). This suggests that the diminished serotonin activity implicated in depression is due to insensitive postsynaptic serotonin receptors. The theory that diminished serotonin activity is due to insensitive serotonin receptors rather than lower absolute levels of serotonin is supported by the pharmacological finding that antidepressants increase levels of neurotransmitters immediately, however, it takes about two weeks (when neurotransmitter levels have returned to their baseline 
levels) before patients experience relief from antidepressant treatment; it is also supported by metabolic studies that indicate that some individuals with depression do not show evidence of abnormal absolute neurotransmitter levels (Kring et al., 2007, pp. 238-240). While the serotonin hypothesis is inevitably an oversimplification, diminished activity in the serotonin system is likely to be involved in depression.

\section{Pharmacological Interventions and the Neurobiology of Mental Disorders}

In the history of twentieth century psychiatry, the development of effective pharmacological treatments for disorders such as schizophrenia and depression played an important role in demonstrating the physical basis of mental disorders and moving psychiatry away from the psychoanalytic and dualist assumptions that dominated American psychiatry until the 1960s. Psychoanalysis enjoyed a period of prestige within American psychiatry from the post-war period until its eventual decline in the 1960s and 1970s (Grob, 1991; Hale, 1995). The “psychopharmacological revolution” of the 1950s (Baumeister and Hawkins, 2005; Bhatara, López-Muñoz, and Gupta, 2005), which featured the pioneering use of pharmacological drugs to treat schizophrenia and depression, was a major contributing factor in the demise of psychoanalysis. Within psychoanalytically oriented psychiatry, mental disorders such as schizophrenia and depression were conceived of as the externalization of subconscious and traumatic personality conflicts, and it was thought that genuine treatment required patients to discover the roots of their internal conflicts (López-Muñoz and Alamo, 2009). From this perspective, the development of pharmacological drugs to treat mental disorders was regarded with skepticism by psychoanalysts since it was thought that these drugs would merely mask the symptoms of these disorders and these drugs could not address the underlying mental conflicts 
that genuine treatment required. The success of pharmacological treatments for mental disorders contributed to the debunking of these psychoanalytic and dualist assumptions and, eventually, to the replacement of psychoanalytically-oriented psychiatry with biological psychiatry.

In addition to their contribution to demonstrating the physical basis for some mental disorders, pharmacological drugs played a crucial epistemic role in as experimental instruments that allowed researchers to formulate the first biological, etiological theories about mental disorders. Pharmacological drugs facilitated the formulation of neurobiological hypotheses by allowing researchers to draw inferences about the neurobiological causes of mental disorders based on how clinical populations of patients responded to particular drug interventions. In this process, drugs operate as instruments or technologies that reveal important causal regularities underlying mental disorders. In the case of schizophrenia, the fact that typical antipsychotic drugs are dopamine antagonists facilitated the formulation of the original dopamine hypothesis that maintained that schizophrenia is caused by excessive dopamine activity. In depression, the fact that first generation antidepressants are monoamine agonists facilitated the formulation of the monoamine hypothesis that maintained that depression is caused by deficient activity of monoamine neurotransmitters.

The way in which pharmacological interventions facilitate the generation of neurobiological hypotheses exemplifies the interventionist kind of causal reasoning that has been examined comprehensively by James Woodward (2003). Woodward (2003, ch. 2) advocates a manipulability account of causation that maintains that variable $A$ (e.g., excessive dopamine activity) is a cause of variable $B$ (e.g., psychotic symptoms) if an intervention that can change the value of $A$ (e.g., administering antipsychotic drugs that decrease dopamine activity) results in a 
corresponding change in the value of $B$ (e.g., alleviation of psychotic symptoms). This account of causation is motivated, in part, to capture the role of experimentation in causal inference. On Woodward's view, experimentation is relevant to the generation of causal claims because these claims have implications concerning what would happen to $B$ under appropriate interventions of A. This view indicates that scientists can distinguish genuine causal relationships between variables (from mere correlations) by way of experimental interventions (cf. Thagard, 1999, chs. 7-8). From this perspective, pharmacological drugs can be viewed as facilitating the generation and formulation of causal hypotheses by providing a means of manipulating variables (e.g., neurobiological variables) that are causally relevant to the appearance of mental disorders.

A related but distinct experimental function of pharmacological drugs is to aid in the testing and confirmation of neurobiological theories. In this epistemic role, pharmacological interventions provide a crucial source of evidence for believing a neurobiological theory, or conversely, reasons for rejecting or revising a theory. For example, the revised dopamine hypothesis that maintains that schizophrenia is caused by a dysregulation of dopamine implies at least two sub-theses:

(1) The positive (psychotic) symptoms of schizophrenia are caused by excessive dopamine activity in the mesolimbic pathway.

(2) The negative symptoms of schizophrenia are caused by deficient dopamine activity in the mesocortical pathway (especially the prefrontal cortex).

Both of these sub-theses are supported by multiple lines of pharmacological research. For example, sub-thesis (1) is primarily supported by the findings that: (i) antipsychotic drugs that decrease dopamine activity in the mesolimbic pathway can alleviate positive symptoms, (ii) the 
antipsychotic effect of such drugs is directly correlated with dopamine blockade strength, (iii) typical antipsychotic drugs exert their influence by blocking $\mathrm{D}_{2}$ dopamine receptors, and (iv) dopamine agonists that increase dopamine activity in the mesolimbic pathway can induce positive symptoms. Taken together, these various pharmacological findings constitute cogent evidence for believing sub-thesis (1).

The way in which pharmacological interventions aid in the confirmation of a neurobiological hypothesis is amenable to philosophical analyses that suggest that a hypothesis is better supported by evidence when multiple lines of independent research converge upon a unified hypothesis (e.g., see Wimsatt, 1981, 2007, ch. 4; Hacking, 1981; Franklin and Howson, 1984; Culp, 1994, 1995; Wylie, 2002, ch. 14; Chang, 2004, ch. 1; Staley, 2004; Stegenga, 2009; Soler et al., 2012). These analyses maintain that a scientific hypothesis or theory is "robust" (i.e., well-confirmed) when multiple lines of (at least partially) independent research all point to a common result. The revised dopamine hypothesis of schizophrenia is robust insofar as multiple lines of independent research support the theory that schizophrenia is caused by a dysregulation of dopamine in the mesolimbic and mesocortical systems. In this regard, it is important to state that pharmacological interventions only constitute one important part of a larger assemblage of research that contributes to the confirmation of a theory. For example, sub-thesis (2) of the dopamine hypothesis is supported by the findings that: (i) typical antipsychotic drugs, which decrease dopamine activity in the prefrontal cortex, exacerbate negative symptoms and cause cognitive impairment, (ii) atypical antipsychotic drugs, which increase dopamine activity in the prefrontal cortex, can alleviate negative symptoms, (iii) NMDA antagonists, which depress dopamine activity in the prefrontal cortex, cause cognitive impairment, (iv) the prefrontal cortex plays a role in speech, decision making, and goal-directed behaviors, which are all disrupted in 
schizophrenia, (v) cognitive impairment is associated deficient dopamine activity in the prefrontal cortex, (vi) schizophrenic patients perform poorly on cognitive tasks designed to measure functions promoted by the prefrontal region, and (vii) brain imaging studies demonstrate that schizophrenic patients fail to show activation in the dorsal prefrontal cortex while performing cognitive tasks (Kring et al., 2007, pp. 366-367; Carlson, 2008, p. 466-467). Within this research, (i)-(iii) are obtained through interventions with pharmacological drugs, whereas (iv)-(vii) are obtained using alternative research methods (e.g., brain imaging studies, cognitive task studies). Similarly, the serotonin hypothesis of depression is supported by various pharmacological interventions, but it is also supported by research adopting alternative research methods (e.g., brain-imaging studies, post-mortem studies, tryptophan depletion studies). This clarifies the sense in which pharmacological interventions play an important—but only partial— role in facilitating the testing and confirmation of neurobiological theories of mental disorders (cf. Bechtel, 2008, pp. 34-39).

An especially valuable epistemic role that pharmacological interventions play in psychiatric research is to promote the refinement, elaboration, and revision of neurobiological theories. In the development of neurobiological theories of schizophrenia and depression, pharmacological drugs played a central role in the elaboration and expansion of these theories. In this process, researchers used the known causal effects of various drugs to revise and refine neurobiological theories (e.g., the revision of the monoamine hypothesis to the serotonin hypothesis of depression). Moreover, knowledge about the different clinical profiles of various drugs — in conjunction with knowledge about different neurotransmitter systems in the brainallowed researchers to identify distinct neurobiological causes for different symptoms of mental disorders (e.g., the positive and negative symptoms of schizophrenia). An important technique 
that researchers utilized to gain such knowledge was the comparison of drugs with clinical profiles that varied in slight ways (e.g., having a weaker serotonin blockade effect, having a higher affinity for $\mathrm{D}_{2}$ receptors), which allowed for causal inferences to be drawn based on the differential response of patients to such drugs.

The way in which pharmacological interventions facilitate the refinement and revision of neurobiological theories of mental disorders highlights the dynamic and interactive relationship between clinical contexts (applied science) and research contexts (pure science) in psychiatry. While pharmacological research is motivated primarily to design better pharmacological treatments in clinical contexts (e.g., creating drugs with fewer unwanted side-effects), the drugs that are developed often play a crucial role in assisting researchers to expand and revise existing neurobiological theories of mental disorders in research contexts. Martin Carrier (2004a, 2010) has argued that the aims of applied science (viz., pragmatic control) — which are embedded in a particular context of interests, values, and practical problems_-do not necessarily compromise the aims of pure science (viz., knowledge acquisition). Moreover, he suggests that innovative discoveries in pure science often arise through applied research projects, which is a process he calls application innovation (Carrier, 2004a, 2004b, 2010). The ways in which neurobiological theories of mental disorders have been expanded and revised through applied research in pharmacology represents a particularly salient example of application innovation. Conversely, theoretical innovations in neurobiological research often feed back into applied contexts to facilitate the development of better pharmacological treatments (Thagard, 2003, 2008). This highlights the manner in which applied and pure contexts in psychiatry stand in an interactive and complementary relationship. 


\section{Conclusion}

This paper examined the ways in which pharmacological interventions with psychiatric patients have played a central role in the formulation, testing, and elaboration of neurobiological theories of schizophrenia and depression. In this process, pharmacological drugs function as experimental instruments that allow researchers to draw causal inferences about the neural pathways and activities responsible for the psychological and behavioral signs of mental disorders (e.g., delusions, feelings of sadness, cognitive impairment). This analysis also emphasized how innovative pharmacological developments in clinical contexts (i.e., in the development of pharmacological treatments for mental disorders) serve to further knowledge in research contexts (i.e., in the evolution of neurobiological theories of mental disorders). While the knowledge acquired in this process is not known with certainty or immune from revision, pharmacological interventions with clinical populations of psychiatric patients have provided an indispensable source of evidence in the articulation of modern biological theories of mental disorders.

Seen from a broader historical perspective, pharmacological interventions with psychiatric patients paved the path towards a physical understanding of mental disorders. In particular, the psychopharmacology revolution contributed to the downfall of psychoanalytic and dualist theories of psychopathology in the 1960s and 1970s, and it set the foundations for the emerging biological approach to psychiatry that would eventually supplant psychoanalysis. The psychopharmacological revolution—-through its influence on neurobiology—also contributed to the idea that many psychological constructs examined by psychiatrists that were thought to be ineliminably “mental” (e.g., 'delusion,' ‘sadness’) could be explained and understood in physical terms. While this does not imply that social and psychological variables are unimportant in the study of psychopathology or the treatment of mental disorders, it does suggest that the attempt to 
study psychopathology purely at the level of a non-physical "mental realm" that is inaccessible by physical means is unlikely to promote progress in psychiatry or in the treatment of mental disorders.

\section{Acknowledgements}

This chapter draws on materials originally developed in Tsou (2012, 2013). I am grateful to Ian Hacking, William Wimsatt, Emma Tobin, and Philip Seeman for helpful comments and suggestions on issues discussed in this chapter.

\section{References}

Abi-Dargham, A. (2004). Do we still believe in the dopamine hypothesis? New data bring new evidence. International Journal of Neuropsychopharmacology, 6 (Suppl.), S1-S5.

Ackermann, R. J. (1985). Data, instruments, and theory: A dialectical approach to understanding science. Princeton, NJ: Princeton University Press.

Andreasen, N. C, and Olsen, S. (1982). Negative $v$ positive schizophrenia: Definition and validation. Archives of General Psychiatry, 39(7), 789-794.

Angst, J., Jaenicke, U., Padrutt, A., \& Scharfetter, C. (1971). Ergebnisse eines Doppelblindversuchs von Clozapin (8-Chlor-11-(4-methyl-1-piperazinyl)-5-Hdibenzo(b,e)(1,4)diazepin im Vergleich zu Levomepromazin. Pharmakopsychiatrie, 4(4), 192200.

Åsberg, M., Träskmann, L., \& Thorén, P. (1976). 5-HIAA in the cerebrospinal fluid: A biochemical suicide predictor? Archives of General Psychiatry, 33(10), 1193-1197.

Ayd, F. J. (1961). A survey of drug-induced extrapyradmidal reactions. Journal of the American Medical Association, 175(12), 1054-1060.

Ban, T. A. (1994). Nobel Prize and Albert Lasker Award. In T. A. Ban \& H. Hippius (Eds.), Towards CINP (pp. 8-14). Brentwood, TN: JM Productions. 
Ban, T. A. (2007). Fifty years chlorpromazine: A historical perspective. Neuropsychiatric Disease and Treatment, 3(4), 495-500.

Baumeister, A. A., \& Hawkins, M. F. (2005). Continuity and discontinuity in the historical development of modern psychopharmacology. Journal of the History of the Neurosciences, 14(3), 199-209.

Bechtel, W. (2008). Mental mechanisms: Philosophical perspectives on cognitive neuroscience. New York: Routledge.

Benkelfat, C., Ellenbogen, M. A., Dean, P., Palmour, R. M., \& Young, S. N. (1994). Moodlowering effect of tryptophan depletion: Enhanced susceptibility in young men at genetic risk for major affective disorders. Archives of General Psychiatry, 51(9), 687-700.

Bente, D., Engelmeier, M.-P., Heinrich, K., Schmitt, W., \& Hippius, H. (1966). Klinische Untersungen mit einem neuroleptisch wirksamen Dibenzothiazepin-Derivat. Arzneimittelforschung, 16(2), 314-316.

Bhatara, V. S., López-Muñoz, R., \& Gupta, S. (2005). Celebrating the 50th anniversary of the introduction of chlorpromazine in North America and the advent of the psychopharmacology revolution. Annals of Clinical Psychiatry, 17(3), 109-111.

Carlson, N. R. (2008). Foundations of physiological psychology (7th ed.). Boston, MA: Allyn and Bacon.

Carrier, M. (2004a). Knowledge and control: On the bearing of epistemic values in applied science. In P. Machamer \& G. Wolters (Eds.), Science, values, and objectivity (pp. 275-293). Pittsburgh, PA: University of Pittsburgh Press.

Carrier, M. (2004b). Knowledge gain and practical use: Models in pure and applied research. In D. Gillies (Ed.), Laws and models in science (pp. 1-17). London: King's College Publications.

Carrier, M. (2010). Theories for use: On the bearing of basic science on practical problems. In M. Suárez, M. Dorato, \& M. Rédei (Eds.), EPSA epistemology and methodology of science: Launch of the European Philosophy of Science Association (pp. 23-33). Dordrecht: Springer.

Cartwright, N. (1983). How the laws of physics lie. Oxford: Oxford University Press.

Chang, H. (2004). Inventing temperature: Measurement and scientific progress. Oxford: Oxford University Press.

Coppen, A. (1967). The biochemistry of affective disorders. British Journal of Psychiatry, 113(504), 1237-1264.

Crow, T. J. (1980a). Molecular pathology of schizophrenia: More than one disease process? British Medical Journal, 280(6207), 1-9. 
Crow, T. J. (1980b). Positive and negative schizophrenia symptoms and the role of dopamine. British Journal of Psychiatry, 137(4), 383-386.

Culp, S. (1994). Defending robustness: The bacterial mesosome as a test case. In D. Hull, M. Forbes, \& R. M. Burian (Eds.), PSA 1994: Proceedings of the 1994 Biennial Meeting of the Philosophy of Science Association (Vol. 1, pp. 46-57). East Lansing, MI: Philosophy of Science Association.

Culp, S. (1995). Objectivity in experimental inquiry: Breaking data-technique circles. Philosophy of Science, 62(3), 430-450.

Davis, K. L., Kahn, R. S., Ko, G., \& Davidson, M. (1991). Dopamine in schizophrenia: A review and reconceptualization. American Journal of Psychiatry, 148(11), 1474-1486.

Delay, J., \& Deniker, P. (1952). 38 cas de psychoses traitées par la cure prolongée et continué de 4560 RP. Comptes rendus du 50e congrès des médecins aliénistes et neurologistes de France et des pays de langue française, 50, 503-513.

Ellinwood, E. H. (1967). Amphetamine psychosis: I. Description of the individuals and process. Journal of Nervous and Mental Disease, 144(4), 273-283.

Ellinwood, E. H., Sudilovsky, A., \& Nelson, L. M. (1973). Evolving behavior in the clinical and experimental amphetamine (model) psychosis. American Journal of Psychiatry, 130(10), 1088-1093.

Fangmann, P., Assion, H.-J., Juckel, G., González, C. Á., \& López-Muñoz, F. (2008). Half a century of antidepressant drugs: On the clinical introduction of monoamine oxidase inhibitors, tricyclics, and tetracyclics. Part II: Tricyclics and tetracyclics. Journal of Clinical Psychopharmacology, 28(1), 1-4.

Feighner, J. P. (1983). The new generation of antidepressants. Journal of Clinical Psychiatry, 44(5 Pt 2) 49-55.

Franklin, A. (1986). The neglect of experiment. Cambridge: Cambridge University Press.

Franklin, A. (1996). There are no antirealists in the laboratory. In R. S. Cohen, R. Hilpinen, \& Q. Renzong (Eds.), Realism and antirealism in the philosophy of science (pp. 131-148). Dordrecht: Kluwer Academic Publishers.

Franklin, A. (2010). Experiment in physics. In E. N. Zalta (Ed.), The Stanford encyclopedia of philosophy (Spring 2010 ed.). <http://plato.stanford.edu/archives/ spr2010/entries/physics-experiment/>.

Franklin, A., \& Howson, C. (1984). Why do scientists prefer to vary their experiments? Studies in History and Philosophy of Science, 15(1), 51-62. 
Giere, R. N. (1988). Explaining science: A cognitive approach. Chicago: University of Chicago Press.

Grob, G. N. (1991). Origins of DSM-I: A study in appearance and reality. American Journal of Psychiatry, 148(4), 421-431.

Gross, H., \& Langner, E. (1966). Das Wirkungsprofil eines chemisch neuartigen Breitbandneuroleptikums der Dibenzodiazepingruppe. Wiener Medizinische Wochenschrift, 116, 814-816.

Hacking, I. (1981). Do we see through a microscope? Pacific Philosophical Quarterly, 62(4), 305-322.

Hacking, I. (1983). Representing and intervening: Introductory topics in the philosophy of natural science. Cambridge: Cambridge University Press.

Hale, N. G. (1995). The rise and crisis of psychoanalysis in America: Freud and the Americans, 1917-1985. Oxford: Oxford University Press.

Healy, D. (1997). The antidepressant era. Cambridge, MA: Harvard University Press.

Healy, D. (2002). The creation of psychopharmacology. Cambridge, MA: Harvard University Press.

Healy, D. (2004). Drug regulation and the introduction of psychotropic drugs in the United Kingdom. In T. A. Ban, D. Healy, \& E. Shorter (Eds.), Reflections on twentieth-century psychopharmacology (pp. 94-97). Budapest: Animula.

Hippius, H. (1989). The history of clozapine. Psychopharmacology, 99 (Suppl.), S3-S5.

Hippius, H. (1996). The founding of the CINP and the discovery of clozapine. In D. Healy (Ed.), The psychopharmacologists: Interviews (Vol. 1, pp. 187-214). London: Chapman and Hall.

Hirschfeld, R. M. A. (2000). History and evolution of the monoamine hypothesis of depression. Journal of Clinical Psychiatry, 61(Suppl. 6), 4-6.

Janowsky, D. S. (2004). The history of psychotropic drugs in the United States. In T. A. Ban, D. Healy, \& E. Shorter (Eds.), Reflections on twentieth-century psychopharmacology (pp. 77-82). Budapest: Animula.

Johnson, S. L., Joormann, J., LeMoult, J., \& Miller, C. (2009). Mood disorders: Biological bases. In P. H. Blaney \& T. Millon (Eds.), Oxford textbook of psychopathology, 2nd ed. (pp. 198-229). New York: Oxford University Press.

Kane, J., Honigfeld, G., Singer, J., Meltzer, H., \& the Clozaril Collaborative Study Group (1988). Clozapine for the treatment-resistant schizophrenic: A double blind comparison with chlorpromazine. Archives of General Psychiatry, 45(9), 789-796. 
Kendler, K. S., \& Schaffner, K. F. (2011). The dopamine hypothesis of schizophrenia: An historical and philosophical analysis. Philosophy, Psychiatry, \& Psychology, 18(1), 41-63.

Klerman, G. L., \& Cole, J. O. (1965). Clinical pharmacology of imipramine and related antidepressant compounds. Pharmacological Review, 17(2), 101-141.

Kring, A. M., Davison, G. C., Neale, J. M., \& Johnson, S. L. (2007). Abnormal psychology (10th ed.). Hoboken, NJ: John Wiley \& Sons.

Laborit, H., \& Huguenard, P. (1951). L'hibernation artificielle par moyens pharmacodynamiques of physiques. La presse médicale, 59(64), 1329.

Laing, R. D. (1967). The politics of experience. New York: Ballantine.

Lehmann, H. E., Cahn, C. H., \& De Verteuil, R. L. (1958). The treatment of depressive conditions with imipramine (G 22355). Canadian Psychiatric Association Journal, 3(4), 155164.

López-Muñoz, F., \& Alamo, C. (2009). Monoaminergic neurotransmission: The history of the discovery of antidepressants from 1950s to today. Current Pharmaceutical Design, 15(14), 1563-1586.

López-Muñoz, F., Álamo, C., Ceunza, E., Shen, W. W., Clervoy, P., \& Rubio, G. (2005). History of the discovery and clinical introduction of chlorpromazine. Annals of Clinical Psychiatry, 17(3), 113-135.

López-Muñoz, F., Álamo, C., Jucle;, G., \& Assion, H.-J. (2007). Half a century of antdepressant drugs: On the clinical introduction of monoamine oxidase inhibitors, tricyclics, and tetracyclics. Part I: Monoamine oxidase inhibitors. Journal of Clinical Psychopharmacology, 27(6), 555-559.

Mann, J. J. (1998). The neurobiology of suicide. Nature Medicine, 4(1), 25-30.

McKim, W. A. (2007). Drugs and behavior: An introduction to behavioral pharmacology $\left(6^{\text {th }}\right.$ ed.). Upper Saddle River, NJ: Pearson Prentice Hall.

Moore, P., Landolt, H. P., Seifritz, E., Clark, C., Bhatti, T., Kelsoe, J., Rapaport, M., \& Gillin, J. C. (2000). Clinical and physiological consequences of rapid tryptophan depletion.

Neuropsychopharmacology, 23(6), 601-622.

Morrison, M. (1990). Theory, intervention, and realism. Synthese, 82(1), 1-22.

Roy, A., De Jong, J., \& Linnoila, M. (1989). Cerebrospinal fluid monoamine metabolites and suicidal behavior in depressed patients: A 5-year follow-up study. Archives of General Psychiatry, 46(7), 609-612.

Sachar, E. J., \& Baron, M. (1979). The biology of affective disorders. Annual Review of Neuroscience, 2, 515-518. 
Sawaguchi, T., \& Goldman-Rakic, P. S. (1994). The role of D1-dopamine receptor in working memory: Local injections of dopamine antagonists into the prefrontal cortex of rhesus monkeys performing an oculomotor delayed-response task. Journal of Neurophysiology, 71(2), 515-528.

Scheff, T. J. (1963). The role of the mentally ill and the dynamics of disorder: a research framework. Sociometry, 26(4): 436-453.

Seeman, P., Chau-Wong, M., Tedesco, J, and Wong, K. (1975). Brain receptors for antipsychotic drugs and dopamine: Direct binding assays. Proceedings of the National Academy of Science, 72(11): 4376-4380.

Shen, W. W. (1999). A history of antipsychotic drug development. Comprehensive Psychiatry, 40(6), 407-414.

Soler, L., Trizio, E., Nickles, T., \& Wimsatt, W. C. (Eds.) (2012). Characterizing the robustness in science: After the practice turn in philosophy of science. Dordrecht: Springer.

Staley, K. W. (2004). Robust evidence and secure evidence claims. Philosophy of Science, 71(4), 467-488.

Stegenga, J. (2009). Robustness, discordance, and relevance. Philosophy of Science, 76(5), 650661.

Strauss, J. S., Carpenter, W. T. \& Bartko, J. J. (1974). Speculations on the processes that underlie schizophrenic symptoms and signs. Schizophrenia Bulletin, 1(11), 61-69.

Szasz, T. S. (1960). The myth of mental illness. American Psychologist 15(2): 113-115.

Thagard, P. (1999). How scientists explain disease. Princeton, NJ: Princeton University Press.

Thagard, P. (2003). Pathways to biomedical discovery. Philosophy of Science, 70(2), 235-254.

Thagard, P. (2008). Mental illness from the perspective of theoretical neuroscience. Perspectives in Biology and Medicine, 51(3), 335-352.

Träskmann, L., Åsberg, M., Bertilsson, L., \& Sjöstrand, L. (1981). Monoamine metabolites in CSF and suicidal behavior. Archives of General Psychiatry, 38(6), 631-636.

Tsou, J. Y. (2012). Intervention, causal reasoning, and the neurobiology of mental disorders: Pharmacological drugs as experimental instruments. Studies in History and Philosophy of Biological and Biomedical Sciences, 43(2), 542-551.

Tsou, J. Y. (2013). Depression and suicide are natural kinds: Implications for physician-assisted suicide. International Journal of Law and Psychiatry, 36(5-6), 461-470. 
Wimsatt, W. C. (1981). Robustness, reliability, and overdetermination. In M. B. Brewer \& B. E. Collins (Eds.), Scientific inquiry and the social sciences (pp. 124-163). San Francisco, CA:

Jossey-Bass.

Wimsatt, W. C. (2007). Re-engineering philosophy for limited beings: Piecewise approximations to reality. Cambridge, MA: Harvard University Press.

Wing, J. K. (1978). Clinical concepts of schizophrenia. In J. K. Wing (Ed.) Schizophrenia:

Towards a new synthesis (pp. 1-30). New York: Grune \& Stratton.

Wong, D. T., Horng, J. S., Bymaster, F. P., Hauser, K. L., \& Molloy, B. B. (1974). A selective inhibitor of serotonin uptake: Lilly 110140, 3-(p-trifluoromethylphenoxy)-N-Methyl-3-

Phenylpropylamine. Life Sciences, 15(3), 471-479.

Wong, D. T., Perry, K. W., \& Bymaster, F. P. (2005). The discovery of fluoxetine hydrochloride (Prozac). Nature Reviews Drug Discovery, 4(9), 764-774.

Woodward, J. (2003). Making things happen: A theory of causal explanation. Oxford: Oxford University Press.

Woodward, J. F. (2008). Cause and explanation in psychiatry: An interventionist perspective. In K. S. Kendler \& J. Parnas (Eds.), Philosophical issues in psychiatry: Explanation, phenomenology, and nosology (pp. 132-195). Baltimore, MD: Johns Hopkins University Press.

Wylie, A. (2002). Thinking from things: Essays in the philosophy of archaeology. Berkley, CA: University of California Press. 